\title{
Electron transport properties in
}

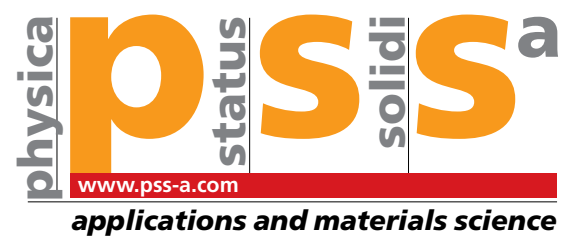

\section{$\mathrm{Al}_{0.25} \mathrm{Ga}_{0.75} \mathrm{~N} / \mathrm{AIN} / \mathrm{GaN}$ heterostructures with different InGaN back barrier layers and GaN channel thicknesses grown by MOCVD}

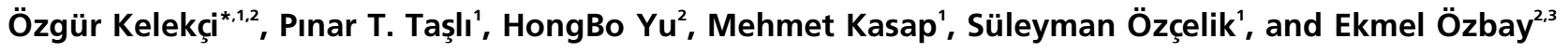 \\ ${ }^{1}$ Faculty of Science and Arts, Department of Physics, Gazi University, Teknikokullar, 06500 Ankara, Turkey \\ ${ }^{2}$ Nanotechnology Research Center, Bilkent University, Bilkent, 06800 Ankara, Turkey \\ ${ }^{3}$ Department of Physics, Bilkent University, Bilkent, 06800 Ankara, Turkey
}

Received 5 July 2011, revised 23 December 2011, accepted 23 December 2011

Published online 24 January 2012

Keywords back barrier, electron transport, GaN HEMT, scattering

*Corresponding author: e-mail okelekci@bilkent.edu.tr, Phone: +90 312 2903050, Fax: +90 3122901015

The electron transport properties in $\mathrm{Al}_{0.25} \mathrm{Ga}_{0.75} \mathrm{~N} / \mathrm{AlN} / \mathrm{GaN} /$ $\mathrm{In}_{x} \mathrm{Ga}_{1-x} \mathrm{~N} / \mathrm{GaN}$ double heterostructures with various indium compositions and $\mathrm{GaN}$ channel thicknesses were investigated. Samples were grown on $c$-plane sapphire substrates by MOCVD and evaluated using variable temperature Hall effect measurements. In order to understand the observed transport properties, various scattering mechanisms, such as acoustic phonon, optical phonon, interface roughness, background impurity, and alloy disorder, were included in the theoretical model that was applied to the temperature-dependent mobility data. It was found that low temperature $(T<160 \mathrm{~K})$ mobility is limited only by the interface roughness scattering mechanism, while at high temperatures $(T>160 \mathrm{~K})$, optical phonon scattering is the dominant scattering mechanism for AlGaN/ AlN/GaN/InGaN/GaN heterostructures. The higher mobility of the structures with InGaN back barriers was attributed to the large conduction band discontinuity obtained at the channel/ buffer interface, which leads to better electron confinement.
1 Introduction Due to their superior material properties, such as large band gap, large breakdown field, and high saturation velocity, nitride-based semiconductors have attracted a great deal of attention for high power and high frequency applications [1, 2]. In order to improve the performance of devices, various barriers and channel alternatives were exploited in nitride-based HEMTs [3-7]. Important progress has been made with improvements in the material quality, device fabrication, and the epitaxial layer designs. An AlN interlayer has been inserted between the $\mathrm{AlGaN}$ barrier and $\mathrm{GaN}$ layer, which makes polarization effects stronger and this causes a higher sheet carrier density. Additionally, due to less alloy disorder scattering, a higher mobility has been achieved [3]. It has been reported that the incorporation of an InGaN layer between an $\mathrm{AlGaN}$ barrier and a $\mathrm{GaN}$ channel in conventional heterostructures leads to a higher carrier density that is induced by larger polarization fields and a better confinement at the interface due to the larger conduction band offset [4]. However, it has been quite difficult to grow a cluster-free high quality InGaN channel layer, so the mobility of two-dimensional electron gas (2DEG) in the InGaN channel has been lower when compared to conventional AlGaN/GaN HEMT structures [4]. Thin InGaN layers have also been employed as back barriers in order to increase the confinement of electrons in the channel by increasing the conduction band offset of the GaN buffer with respect to the GaN channel [8-11].

Despite these studies that have been reported in the literature, there are not any reports in terms of the detailed analysis of the transport characteristics of HEMTs with the InGaN back barrier. As the first step in realizing a high performance $\mathrm{AlGaN} / \mathrm{AlN} / \mathrm{GaN} / \mathrm{InGaN} / \mathrm{GaN}$ HEMT structure, it is very important to understand its basic electron transport properties, which have not been studied systematically. In this work, we investigate the electron transport properties in AlGaN/AlN/GaN/InGaN/GaN double heterostructures with different InGaN back barriers and $\mathrm{GaN}$ channel thicknesses using variable temperature Hall effect 
measurements. Analytical models were applied to the experimental data in order to understand scattering mechanisms that govern the transport properties of the structures in a temperature range of $30-300 \mathrm{~K}$.

2 Experimental details $\mathrm{Al}_{0.25} \mathrm{Ga}_{0.75} \mathrm{~N} / \mathrm{AlN} / \mathrm{GaN} /$ $\mathrm{In}_{x} \mathrm{Ga}_{1-x} \mathrm{~N} / \mathrm{GaN}$ HEMT structures were grown on $2 \mathrm{in}$. (0001) sapphire substrates in a vertical low pressure metalorganic chemical vapor deposition (MOCVD) system. Prior to epitaxial growth, the sapphire substrate was annealed at $1050^{\circ} \mathrm{C}$ for $15 \mathrm{~min}$ in order to remove surface contamination. The growth was initiated with a $15 \mathrm{~nm}$ thick low temperature (LT) AlN nucleation layer at a temperature of $5500{ }^{\circ} \mathrm{C}$. Then, a $520 \mathrm{~nm}$ high temperature (HT) AlN buffer layer (BL) was grown at a temperature of $11500^{\circ} \mathrm{C}$. A $1.3 \mu \mathrm{m}$ thick nominally undoped GaN BL was then grown at $10500{ }^{\circ} \mathrm{C}$ and a reactor pressure of $200 \mathrm{mbar}$. After the $\mathrm{GaN}$ $\mathrm{BL}, \mathrm{InGaN}$ back barrier layers were grown at a temperature range of $7400-7950{ }^{\circ} \mathrm{C}$ with a pressure of $200 \mathrm{mbar}$. The growth temperature and time were adjusted in order to obtain InGaN back barrier layers with the desired thickness and Indium composition. Following this layer, a GaN channel layer was grown at the same temperature as the $\mathrm{InGaN}$ back barrier layer. In order to reduce the alloy disorder scattering (ALLOY), a $\sim 1 \mathrm{~nm}$ thick HT AlN inter layer was grown at a temperature of $10750^{\circ} \mathrm{C}$. A $25 \mathrm{~nm}$ AlGaN barrier layer was deposited on an AlN inter layer at a growth temperature of $10750{ }^{\circ} \mathrm{C}$. The growths were finalized by growing a $3 \mathrm{~nm}$ thick $\mathrm{GaN}$ cap layer at $10750^{\circ} \mathrm{C}$. All the layers are nominally undoped. As a reference, one sample was grown without an InGaN back barrier layer. The indium compositions of the back barrier layers were determined by high resolution X-ray diffraction (XRD) measurements. The details of all the samples are shown in Table 1.

Variable temperature Hall measurements were used to measure the 2DEG mobility and the sheet carrier density for all the samples. For the Hall effect measurements, square shaped samples in Van der Pauw geometry were prepared with four evaporated $\mathrm{Ti} / \mathrm{Al} / \mathrm{Ni} / \mathrm{Au}$ triangular Ohmic contacts

Table 1 Summary of the main structural parameters of the samples and Hall measurement results at room temperature.

\begin{tabular}{lllllll}
\hline sample & $\mathrm{A}^{\mathrm{a}}$ & $\mathrm{B}$ & $\mathrm{C}$ & $\mathrm{D}$ & $\mathrm{E}$ & $\mathrm{F}$ \\
\hline $\begin{array}{l}\text { In composition of } \\
\text { back barrier (\%) }\end{array}$ & - & 10 & 10 & 20 & 5 & 15 \\
$\begin{array}{l}\text { GaN channel } \\
\text { thickness }(\mathrm{nm})\end{array}$ & - & 5 & 10 & 15 & 10 & 10 \\
$\begin{array}{l}\text { mobility at } \\
300 \mathrm{~K}\left(\mathrm{~cm}^{2} / \mathrm{Vs}\right)\end{array}$ & 1029 & 872 & 1294 & 1029 & 1367 & 1186 \\
$\begin{array}{l}2 \mathrm{DEG} \text { density } \\
\text { at } 300 \mathrm{~K}\left(\times 10^{13} \mathrm{~cm}^{-2}\right)\end{array}$ & 1.32 & 1.52 & 1.21 & 1.27 & 1.36 & 1.41 \\
$\begin{array}{l}\text { sheet resistance } \\
\text { at } 300 \mathrm{~K}(\Omega / \mathrm{sq})\end{array}$ & 460 & 471 & 399 & 478 & 336 & 374 \\
\hline
\end{tabular}

${ }^{\mathrm{a}}$ Control sample. at the corners. The ohmic behavior of the contacts was confirmed by the current-voltage $(I-V)$ characteristics. The measurements were performed at various temperatures over a temperature range of 30-300 K by using a Lake Shore Hall effect measurement system.

3 Results and discussion The conduction band profile and carrier distribution for the AlGaN/AlN/GaN and $\mathrm{AlGaN} / \mathrm{AlN} / \mathrm{GaN} / \mathrm{InGaN} / \mathrm{GaN}$ structures is calculated by solving one-dimensional non-linear Schrödinger-Poisson equations, self-consistently including polarization induced carriers [12]. The conduction band profile, carrier distribution, and general structure of the AlGaN/AlN/GaN/InGaN/GaN HEMT are plotted in Fig. 1, along with that of a conventional AlGaN/AlN/GaN HEMT. It is clearly seen from Fig. 1b that the InGaN back barrier layer significantly improves the electron confinement in the channel by introducing a conduction band discontinuity at the channel/buffer interface.

Hall measurements of the grown samples as a function of the temperature $(30-300 \mathrm{~K})$ were carried out at a constant magnetic field $(0.4 \mathrm{~T})$. Figure $2 \mathrm{a}$ and $\mathrm{b}$ shows Hall measurement results as a function of temperature for the mobility and carrier density for all the samples, respectively. As shown Fig. 2a and b, while the mobilities of all the samples decrease with increasing temperature, they are independent of temperature at LTs. In addition, the carrier densities of the samples are also almost independent of temperature in the measured temperature range. These behaviors of mobilities and sheet carrier densities extracted from Hall measurements are typical of 2DEG structures. The majority of the samples with InGaN back barriers have higher mobility and carrier density compared to the control sample. Therefore, inserting an InGaN layer between the GaN channel and GaN BL has been effective for enhancing the 2DEG confinement and then improving the mobility.

Accordingly, when samples C, E, and F (which have the same GaN layer thickness but different indium compositions) are compared with each other, sample $C$ has the highest mobility along with the lowest sheet carrier density, whereas, sample $\mathrm{F}$ has the lowest mobility with the highest sheet carrier density. Meanwhile, sample D has relatively low mobility and also low sheet carrier density at the same time, which is generally not expected. The lower mobility


Figure 1 (online color at: www.pss-a.com) (a) Layer structures of the investigated samples. (b) Calculated conduction band profile and the carrier distribution of the standard HEMT structure and the structure with InGaN back barrier. 

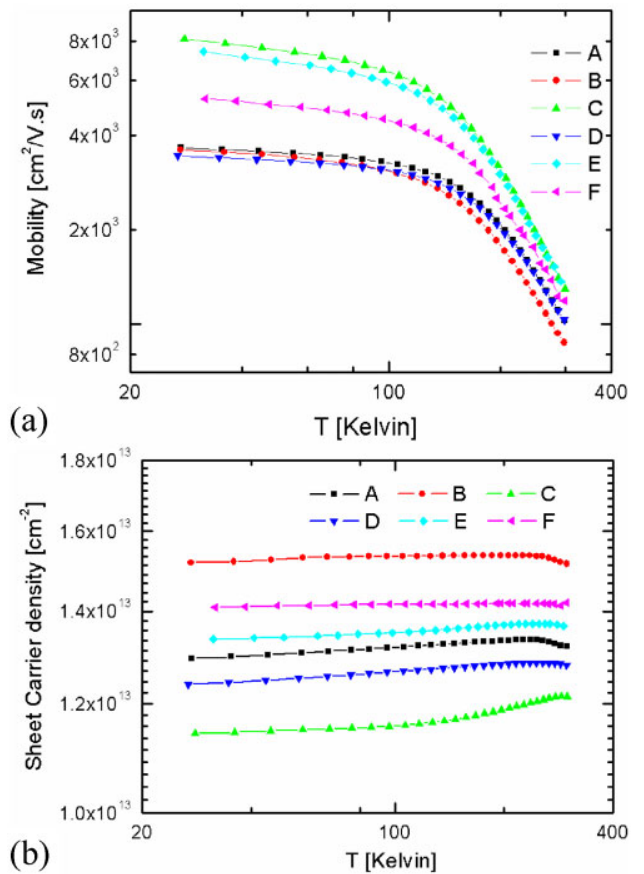

Figure 2 (online color at: www.pss-a.com) Temperature dependence of measured (a) mobility and (b) sheet carrier density for all of the grown samples.

obtained in this sample was attributed to higher indium composition while the low sheet carrier density is caused by higher GaN channel thickness. The conduction band diagrams and sheet carrier densities that were obtained by solving Schrödinger-Poisson's equations for the AlGaN/ AlN/GaN/InGaN/GaN structures with varying GaN channel thickness are shown in Fig. 3. As can be seen in the Fig. 3, the sheet carrier density will decrease with increasing GaN channel thickness because GaN channel's potential is pulled up by the InGaN back barrier layer. Moreover, mobility

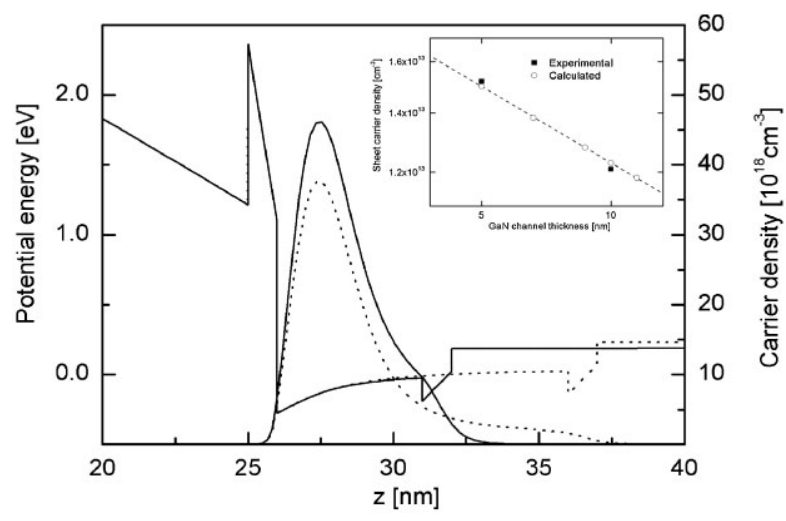

Figure 3 Calculated conduction band profile and carrier distribution along the $z$-axis for the AlGaN/AlN/GaN/InGaN/GaN heterostructures with $5 \mathrm{~nm}$ (solid line) and $10 \mathrm{~nm}$ (dotted line) GaN channel thicknesses. The inset shows the calculated and experimental 2DEG density decrease due to the increasing GaN channel thickness.

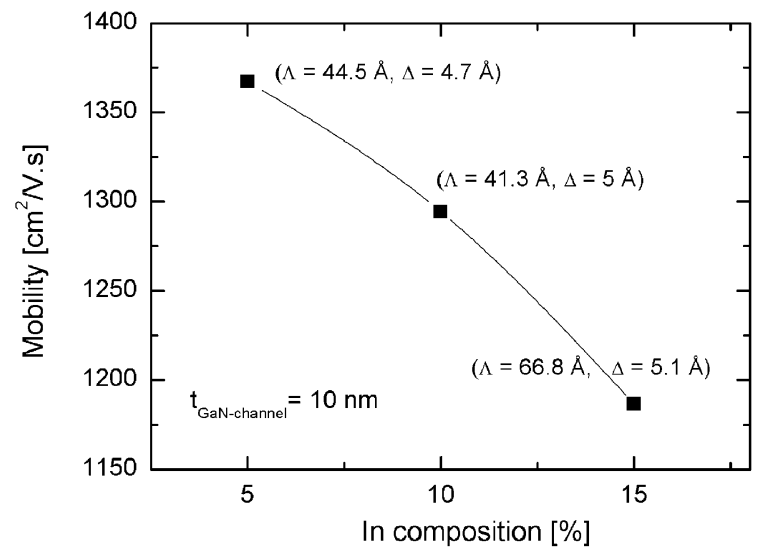

Figure 4 Measured mobility values (along with correlation length $\Lambda$, and lateral size $\Delta$ used in scattering analyses) versus indium composition of the InGaN back barrier layers.

decreases with the increasing indium composition of the InGaN back barrier layer as shown in Fig. 4 .

In order to understand the transport properties of the 2DEG channel formed in the structures, scattering analyses were carried out by using the variable temperature Hall effect measurement data. In our analyses, polar optical phonon scattering (PO), acoustic phonon scattering (AC), background impurity scattering (IMP), interface roughness scattering (IFR), and ALLOY were used. All of the calculated scattering mechanisms are summed up with Matthiessen's rule in order to find the total mobility. The expressions of scattering mechanisms used in these calculations are given elsewhere [13].

The parameters used in these calculations are taken from Ref. [14]. The correlation length $(\Lambda)$, lateral size $(\Delta)$, and quantum well width $\left(Z_{0}\right)$ were taken as free parameters to fit the experimental mobility data and were given in Table 2 . In these calculations, since the measured sheet carrier densities were nearly constant through the whole temperature range, they were accepted as constant. The scattering analyses based on the Hall measurement data show that the LT $(T<160 \mathrm{~K})$ mobility is limited only by the IFR mechanism, while at the HT ( $T>160 \mathrm{~K})$ the optical phonon scattering is the dominant scattering mechanism. Furthermore, the IFR mechanism has a strong influence on the mobility even at HTs. Because of the AlN interlayer used in the structures, alloy scattering is negligible for all of the samples. The effect of AC and IMP are also found to be negligible. In the entire studied temperature range, the strong effect of IFR mechanism results in low mobility. The IFR has been treated

Table 2 Fit parameters used in scattering analyses.

\begin{tabular}{lllllll}
\hline sample & A & B & C & D & E & F \\
\hline$\Lambda(\AA)$ & 102 & 89 & 41.3 & 114 & 44.5 & 66.8 \\
$\Delta(\AA)$ & 5.2 & 5.1 & 5 & 5 & 4.7 & 5.1 \\
$Z_{0}(\mathrm{~nm})$ & 3.8 & 4.8 & 3.3 & 3.5 & 3.3 & 3.5 \\
\hline
\end{tabular}




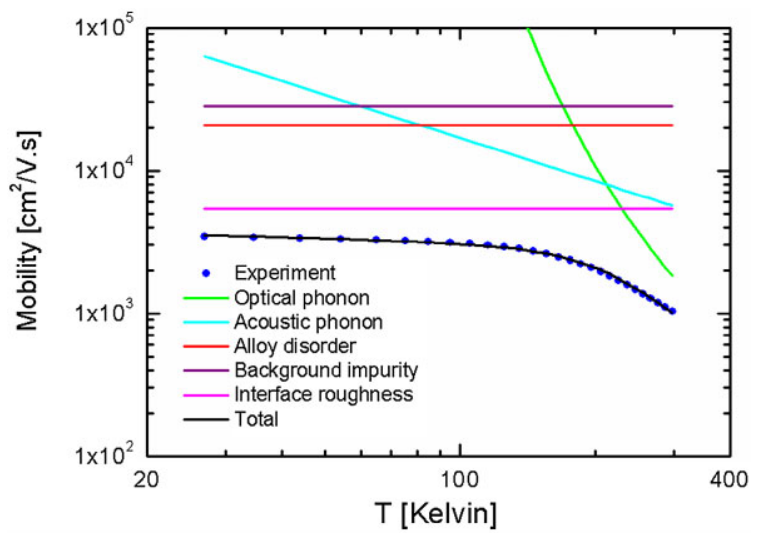

Figure 5 (online color at: www.pss-a.com) The temperature evolution of the measured Hall mobility in comparison with the theoretical calculations including major scattering mechanisms for sample D.

as a combined scattering mechanism which includes effects of all interfaces. The strong effect of IFR can be attributed to the InGaN layer's growth quality, which is also consistent with the literature [15-17].

Scattering analyses have been performed for all of the samples. Scattering analysis of sample D is shown in Fig. 5. IFR observed in this sample is much more dominant when compared to the other samples. The reason for this result is thought to be higher indium composition (20\%) in the back barrier layer when compared to the other samples. Sample B has lower mobility and higher sheet carrier density when compared to sample $\mathrm{C}$ (which has same indium composition with sample B). The difference between sample B and sample $\mathrm{C}$ is the $\mathrm{GaN}$ channel thickness. From the scattering analysis of sample $\mathrm{B}$, it is observed that the optical phonon scattering is much more effective in this sample at HTs. The lower mobility of sample B can be attributed to this scattering mechanism. As the $\mathrm{GaN}$ channel thickness increases from 5 to $10 \mathrm{~nm}$ the quantum well width $\left(Z_{0}\right)$ decreases. This decrease in $Z_{0}$ is also consistent with the results which were obtained by fitting the parameters to experimental data. Mobility contribution coming from PO mechanism is inversely proportional with $Z_{0}\left(\mu_{\mathrm{PO}} \propto Z_{0}^{-1}\right)$ [13]. On the other hand, as can be seen from Fig. 3, sheet carrier density will decrease with increasing GaN channel thickness, because GaN channel's potential is pulled up by the InGaN back barrier layer [8].

4 Conclusion We studied the transport properties of $\mathrm{Al}_{0.25} \mathrm{Ga}_{0.75} \mathrm{~N} / \mathrm{AlN} / \mathrm{GaN} / \mathrm{In}_{x} \mathrm{Ga}_{1-x} \mathrm{~N} / \mathrm{GaN}$ double heterostructures with various indium compositions and $\mathrm{GaN}$ channel thicknesses as well as conventional AlGaN/AlN/ $\mathrm{GaN}$ heterostructures using variable temperature Hall effect measurements. $\quad \mathrm{Al}_{0.25} \mathrm{Ga}_{0.75} \mathrm{~N} / \mathrm{AlN} / \mathrm{GaN} / \mathrm{In}_{x} \mathrm{Ga}_{1-x} \mathrm{~N} / \mathrm{GaN}$ HEMTs with improved 2-DEG density and mobility has been demonstrated on $c$-plane sapphire substrate. It was found that the IFR was the only dominant scattering mechanism at LTs while both the PO and the IFR mechanisms dominated the mobility at HTs. The reason for the strong influence of IFR is attributed to the InGaN layer's crystalline quality. Sample E $\left(\mathrm{Al}_{0.25} \mathrm{Ga}_{0.75} \mathrm{~N} / \mathrm{AlN} /\right.$ $\mathrm{GaN} / \mathrm{In}_{0.05} \mathrm{Ga}_{0.95} \mathrm{~N} / \mathrm{GaN}$, with $t_{\mathrm{GaN}-\text { channel }}=10 \mathrm{~nm}$ ) has been found as the best optimized structure in terms of 2-DEG density and mobility among all of the grown samples. The electron mobility obtained in this double heterostructure is $\left(1367 \mathrm{~cm}^{2} / \mathrm{Vs}\right)$ higher than that of a conventional $\mathrm{Al}_{0.25} \mathrm{Ga}_{0.75} \mathrm{~N} / \mathrm{AlN} / \mathrm{GaN}$ HEMT structure $\left(1029 \mathrm{~cm}^{2} / \mathrm{Vs}\right)$. Therefore, inserting an InGaN layer between the GaN channel and GaN BL has been effective for enhancing the mobility. It is also expected that the employed InGaN layers will increase the carrier confinement within the 2D channel based on calculations. However, this effect will show itself on the sub-threshold leakage current, electron spill-over, and buffer-related trapping which is beyond the scope of this study. Finally, it can be concluded that if the growth conditions and design parameters can be modified further in order to obtain InGaN layers with higher crystalline quality, even higher electron mobilities that result in lower two-dimensional sheet resistances would be possible.

Acknowledgements This work was supported by the State Planning Organization of Turkey under Grant No. 2001K120590, by the European Union under the projects EU-PHOME and EUECONAM, and TUBITAK under the Project Nos. 106E198, 107A004, and 107A012. We would like to thank Dr. B. Sarikavak and Dr. S. B. Lisesivdin for their fruitful discussions.

\section{References}

[1] M. S. Shur, Solid State Electron. 42, 2131 (1998).

[2] U. K. Mishra, L. Shen, T. E. Kazior, and Y.-F. Wu, Proc. IEEE 96, 287 (2008).

[3] L. Shen, S. Heikman, B. Moran, R. Coffie, N.-Q. Zhang, D. Buttari, I. P. Smorchkova, S. Keller, S. P. DenBaars, and U. K. Mishra, IEEE Electron Device Lett. 22, 457 (2001).

[4] G. Simin, A. Koudymov, H. Fatima, J. Zhang, J. Yang, M. A. Khan, X. Hu, A. Tarakji, R. Gaska, and M. S. Shur, IEEE Electron Device Lett. 23, 458 (2002).

[5] R. S. Balmer, K. P. Hilton, K. J. Nash, M. J. Uren, D. J. Wallis, A. Wells, M. Missous, and T. Martin, Phys. Status Solidi C 0, 2331 (2003).

[6] C. M. Wang, X. L. Wang, G. X. Hu, J. X. Wang, J. P. Li, and Z. G. Wang, Appl. Surf. Sci. 253, 762 (2006).

[7] S. Hashimoto, K. Akita, T. Tanabe, H. Nakahata, K. Takeda, and H. Amano, Phys. Status Solidi C 7, 1938 (2010).

[8] J. Liu, Y. Zhou, J. Zhu, K. M. Lau, and K. J. Chen, IEEE Electron Device Lett. 27, 10 (2006).

[9] T. Palacios, A. Chakraborty, S. Heikman, S. Keller, S. P. DenBaars, and U. K. Mishra, IEEE Electron Device Lett. 27, 13 (2006).

[10] J. Tang, X. Wang, H. Xiao, J. Ran, C. Wang, X. Wang, G. Hu, and J. Li, Phys. Status Solidi C 5, 2982 (2008).

[11] V. Adivarahan, M. E. Gaevski, M. Islam, B. Zhang, Y. Deng, and M. A. Khan, IEEE Trans. Electron Devices 55, 495 (2008). 
[12] S. Birner, S. Hackenbuchner, M. Sabathil, G. Zandler, J. A. Majewski, T. Andlauer, T. Zibold, R. Morschl, A. Trellakis, and P. Vogl, Acta Phys. Pol. A 110, 111 (2006).

[13] S. B. Lisesivdin, S. Acar, M. Kasap, S. Ozcelik, S. Gokden, and E. Ozbay, Semicond. Sci. Technol. 22, 543 (2007).

[14] R. Tülek, A. Ilgaz, S. Gökden, A. Teke, M. K. Öztürk, M. Kasap, S. Özçelik, E. Arslan, and E. Özbay, J. Appl. Phys. 105, 013707 (2009).
[15] C. X. Wang, K. Tsubaki, N. Kobayashi, T. Makimoto, and N. Maeda, Appl. Phys. Lett. 84, 2313 (2004).

[16] S. Gökden, R. Tülek, A. Teke, J. H. Leach, Q. Fan, J. Xie, Ü. Özgür, H. Morkoç, S. B. Lisesivdin, and E. Ozbay, Semicond. Sci. Technol. 25, 045024 (2010).

[17] J. Xie, J. H. Leach, X. Ni, M. Wu, R. Shimada, Ü. Özgür, and H. Morkoç, Appl. Phys. Lett. 91, 262102 (2007). 